\title{
A NECESSÁRIA DISCIPLINA DE ORIENTAÇÃO PROFISSIONAL NA FORMAÇÃO DE PROFESSORES PARA O SÉCULO XXI
}

\author{
LA NECESARIA ASIGNATURA DE ORIENTACIÓN PROFESIONAL EN LA \\ FORMACIÓN DE PROFESORES PARA EL SIGLO XXI.
}

\author{
THE NECESSARY DISCIPLINE OF “PROFESSIONAL ORIENTATION” IN \\ TEACHER TRAINING FOR THE 21ST CENTURY
}

RESUMO: O objetivo do artigo é demonstrar resultados de pesquisa realizada pela autora e alunos do curso de Pedagogia da UNESP de Marília. Objetivos: 1) verificar a importância da Orientação Profissional (OP) no curso de formação de professores, o papel que o pedagogo pode desempenhar auxiliando futuros alunos na escolha de uma profissão 2) investigar o que significa para aluno a sua escolha profissional, 3) identificar a concepção que possuem a respeito do tema trabalho, 4) propiciar atividades que estimulem o autoconhecimento e a informação profissional, 5) estimulá-los a elaborarem um projeto de vida pessoal e profissional. Método: pesquisa-ação com base em Thiollent (2008). Foram realizados 10 encontros onde os 13 sujeitos estabeleceram relações interpessoais por meio de discussões, leituras, dinâmicas de grupo e refletiram sobre a multideterminação de sua escolha profissional. Os resultados apontaram que a intervenção pedagógica foi eficaz, visto que a maioria dos sujeitos conseguiu fazer a sua escolha profissional, adquiriram o conceito de trabalho, construíram um projeto de vida pessoal e profissional. Concluímos que o pedagogo pode contribuir com os seus alunos na conscientização dos mesmos, sobre o conceito de trabalho, escolha profissional e da possibilidade do estudo levá-los a alcançar maiores objetivos de vida.

PALAVRAS CHAVE: Orientação Profissional. Curso de Pedagogia. Formação de educadores. Adolescentes.

RESUMEN: El objetivo del artículo es demostrar resultados de la investigación realizada por la autora y alumnos del Curso de Pedagogía de la UNESP de Marília. Objetivos: 1) verificar la importancia de Orientación Profesional (OP) en el Curso de formación de profesores, el papel que el pedagogo puede desempeñar auxiliando futuros alumnos en la selección de una profesión, 2) investigar qué significa para el alumno el hecho de elegir una profesión, 3) identificar la concepción que poseen sobre el tema trabajo, 4) fomentar actividades que estimulen el autoconocimiento y la información profesional, 5) estimularlos para elaborar un proyecto de vida personal y profesional. Método: investigación-acción a la luz de Thiollent (2008). Fueron realizados 10 encuentros donde los 13 sujetos establecieron relaciones interpersonales

\footnotetext{
${ }^{1}$ Professora Assistente Doutora do Departamento de Psicologia da Educação da UNESP de Marília-SP. Coordenadora do Projeto de Extensão Orientação Profissional: universidade ajuda os jovens a fazerem a escolha profissional. Coordenadora da Universidade Aberta da Terceira Idade UNATI - UNESP de Marília-SP. Email: gdatilo@marilia.unesp.br
} 
por medio de discusiones, lecturas, dinámicas de grupo y reflexionaron sobre la multideterminación de su elección profesional. Los resultados mostraron que la intervención pedagógica fue eficaz, una vez que la mayoría de los sujetos consiguió hacer su elección profesional, adquirió el concepto de trabajo, construyó un proyecto de vida personal y profesional. Concluimos que el pedagogo puede contribuir con sus alumnos en la concientización de sus opciones, sobre el concepto de trabajo, elección profesional y de la posibilidad del estudio llevarlos a lograr mejores objetivos de vida.

PALABRAS CLAVE: Orientación Profesional. Carrera de Pedagogía. Formación de educadores "Adolescentes".

ABSTRACT: The objective of this article is to demonstrate the results of a survey conducted by the author and students of Pedagogy UNESP Marilia. Objectives: 1) verify the importance of Career Guidance $(O P)$ in the course of teacher training, the role the teacher can play in assisting prospective students in choosing a profession 2) to investigate what it means for your student career choice, 3) identify the design that have on the subject work, 4) provide activities that encourage self-awareness and professional information, 5) encourage them to develop a project of personal and professional life. Method: action research based on Thiollent (2008). 10 meetings were held where 13 subjects established interpersonal relationships through discussions, readings, group dynamics and reflected on the multiplicity of his career choice. The results showed that the educational intervention was effective, since most of the subjects could make your career choice, acquired the concept of work, and built a project of personal and professional life. We conclude that the teacher can contribute with their students in the same awareness on the concept of work, career choice and the ability of the study to get them to achieve higher goals in life.

KEYWORDS: Career Guidance. Course of Pedagogy. Training of educators. Adolescents.

\section{Introdução}

A Orientação Profissional (OP) nunca foi tão necessária como em tempos de pós modernidade, onde muitas mudanças estão ocorrendo no mundo do trabalho e consequentemente nas profissões, nos cursos, no mercado de trabalho, que é cada vez mais competitivo e exigente e os jovens se vêm "obrigados" a fazerem uma escolha profissional ao final do ensino médio, em plena adolescência.

Partimos da concepção que no curso de formação de professores se faz necessário um olhar para a OP, no sentido de mostrar o papel do pedagogo, e as possibilidades de atuação do pedagogo.

Segundo Oliveira (2000, p.99), esta escolha profissional em plena adolescência nem sempre é um momento tranquilo, ou seja, "o momento da opção do curso nem sempre se baseia na consciência quando os jovens estão vivenciando diversos conflitos inerentes a essa faixa etária, plenos de inconstância, insegurança e angústia." Torna-se então, um 
momento conturbado, que envolve fatores emocionais, sociais, culturais e econômicos, que influenciarão direta ou indiretamente nas possibilidades de escolha dos jovens. Mas o que é escolher uma profissão no século XXI, o que significa "escolher" em uma sociedade em que as oportunidades não são iguais para todos?

Mas essa possibilidade do jovem poder escolher que tipo de curso pretende fazer ou que trabalho pretende exercer apesar das dificuldades diante das inúmeras possibilidades de escolha representa um grande avanço para a humanidade, visto que segundo Bock (2006), a questão da escolha profissional não se constitui como um problema universal da espécie humana. Isto é, só recentemente, levando-se em conta a história da humanidade, os homens se colocam a questão "do que fazer para alcançar sua sobrevivência”. Os nossos ancestrais trabalhavam para sobreviver, isto é, seu trabalho organizava-se como atividade de coleta e mais tarde de caça, para que pudessem se alimentar e manter-se.

Quando as pessoas moravam no campo não se tinham escolhas, a partir de determinada época o menino tinha que ajudar o pai no serviço da lavoura e assim era algo como "destino", o filho traçaria o mesmo caminho de seu pai. A forma como se dava a sobrevivência não dependia de escolhas, as condições estavam estabelecidas aprioristicamente pela estrutura e organização da sociedade. A posição na sociedade era encarada como se fosse uma determinação divina, transmitida de pai para filho. $O$ trabalho visava apenas o sustento das pessoas. Até então, segundo Bock (1995), Ferreti (1997) e Bock (2006), a estrutura social era cristalizada e determinava o que cada um iria fazer, a Igreja legitimava a ordem social, tudo era por vontade divina.

A escolha profissional só assume importância quando de forma definitiva, instala-se o modo de produção capitalista (BOCK, 1995; FERRETI, 1997; BOCK, 2006). Contextualizando um pouco a história da Orientação Profissional, só vimos avançar suas teoria e práticas, no modo capitalista de produção, que mais tarde, na chamada Revolução Industrial, introduzirá a divisão técnica do trabalho. A posição do indivíduo no capitalismo não é mais determinada pelos laços de sangue. Agora, esta posição seria conquistada pelo indivíduo, segundo o esforço que o indivíduo despende para alcançá-la. O conceito de vocação muda, afinal, não se pode mais utilizar a ideia de que "Deus quer que a sociedade seja assim", como se fazia no modo feudal.

A revolução burguesa pregava a ideia de igualdade entre os homens; para justificar as diferenças encontradas no seio da sociedade, desenvolveu o conceito de Vocação Biológica, o orgânico na época explicando as diferenças individuais e sociais. 
Se um individuo "não se deu bem na vida" (não obteve, segundo os parâmetros da sociedade, riqueza, prestigio, poder, etc.), a justificativa para tal gira em torno da má escolha de sua profissão, de não ter encontrado a "verdadeira vocação", ao invés de se proceder segundo Bock (2006), a uma análise da realidade socioeconômica para entender a situação, sobretudo quanto às possibilidades e impossibilidades de escolha dos jovens naquele momento.

O projeto de pesquisa e extensão universitária da PROEX - Pró-reitoria de Extensão Universitária da UNESP de Marília, “Orientação profissional - universidade ajuda os jovens a fazerem a escolha profissional" possibilita o auxílio aos jovens oriundos do ensino médio no momento de escolha profissional, além de oferecer aos estudantes universitários do curso de Pedagogia um novo olhar para a pesquisa, formando o tripé característico das Universidades, que une ensino, pesquisa e extensão, formação necessária para a atuação dos futuros profissionais, principalmente os que atuarão na área da educação, pois estarão diretamente ligados com esses conflitos, sendo muitas vezes responsáveis pelas escolhas, ou melhor, por esse momento de escolha, visto que:

\section{[...] as escolas se constituem, hoje, num importante referencial na vida dos jovens, e, ao lado das FAMÍLIAS, possuem exclusivas oportunidades de contribuição na formação humanística e da cidadania dos jovens, indo muito além da simples proposta de divulgadora de informações e repetidora de conteúdos. (OLIVEIRA, 2000, p.101)}

O contato direto dos estudantes universitários com alunos(as) do ensino médio pode servir também como apoio para esses, pois a pouco aqueles passaram pelas mesmas dúvidas e conflitos, mas conseguiram chegar à escolha profissional. Em alguns momentos dos encontros estudantes de outros cursos da Universidade Estadual PaulistaFFC, campus de Marília, também conversaram com o grupo, esclarecendo dúvidas quanto ao curso e a atuação dos futuros profissionais.

\section{Objetivos}

Verificar o lugar e importância da disciplina de Orientação Profissional (OP) na formação de professores para o século XXI. Investigar o que significa na vida do aluno vestibulando a sua escolha profissional, identificar qual é a concepção que possuem a respeito do tema trabalho. Propiciar atividades que estimulem o autoconhecimento e a 
informação profissional e estimulá-los a elaborarem um projeto de vida pessoal e profissional.

\section{Metodologia}

A presente investigação fundamentou-se na abordagem da pesquisa qualitativa pesquisa-ação, a qual se caracteriza pela participação do pesquisador intervindo, direta ou indiretamente, durante o processo de coleta de dados, visando o desenvolvimento da aprendizagem do sujeito participante da pesquisa, de acordo com o objetivo do trabalho proposto.

Conforme Thiollent (2008, p. 71-72), a pesquisa-ação caracteriza-se por fundamentar:

[...] pesquisas em educação, comunicação e organização acompanham as ações de educar, comunicar e organizar. Os 'atores' sempre têm de gerar, utilizar informações e também orientar a ação, tomar decisões, etc. Isto faz parte tanto da atividade planejada quanto da atividade cotidiana e não pode deixar de ser diretamente observado na pesquisa-ação. As ações investigadas envolvem produção e circulação de informação, elucidação e tomada de decisões, e outros aspectos supondo uma capacidade de aprendizagem dos participantes [...].

Segundo o autor, a pesquisa-ação apresenta-se como uma proposta metodológica e técnica que fundamenta a organização da pesquisa social aplicada, ou seja, possibilita a construção do conhecimento por meio da observação e participação na realidade social, intervenção, processamento dos dados e a experimentação, sendo uma forma flexível de concepção e aplicação da investigação concreta.

Nesse sentido, o processo de intervenção proposto aos sujeitos integrantes do grupo visa à produção de informações, à circulação e principalmente, à conscientização por meio da reflexão dialógica direcionada para tomada de decisões pelos próprios sujeitos quanto à escolha do curso superior.

$\mathrm{O}$ envolvimento entre os integrantes dos grupos ocorreu em diferentes momentos e com as atividades desenvolvidas em cada encontro como, por exemplo, nas atividades de dinâmicas de grupo, nos diálogos estabelecidos (rodas de conversa), nos vídeos que foram apresentados, na socialização dos resultados das pesquisas que foram realizadas por eles, nas "tarefas" de conversar com determinado profissional para saber 
de seu dia-a-dia ou nas pesquisas com os guias de profissões, na internet, na participação dos pais, nos encontros, nas tomadas de decisões a partir dos exercícios propostos como, por exemplo, a "dinâmica do sorvete" proposta por Bock (2006), estimulando-os a refletirem na escolha também como um ato de coragem.

Nessa perspectiva de produção de conhecimento, lembramos Vygotsky (1991), que traz à reflexão a ideia de que o conhecimento não se dá a partir da interação direta sujeito-objeto. Essa interação é, em essência, mediada. Com isso, ele propõe a ideia de mediação, tendo por base a concepção de Marx e Engels, realizada pelos instrumentos e signos.

\section{Instrumentos}

Como instrumentos de conhecimento produzido pelos sujeitos durante os encontros citam-se os questionários, inicial e final, no qual constam reflexões a respeito da escolha profissional, trabalho, mercado e campo de trabalho, projetos de vida, família, autoconhecimento, influências do meio sociocultural, como amizades, família, mídia, colegas de trabalho, bem como filmes, vídeos, textos para reflexão. Tais atividades propostas propiciam a conscientização dos sujeitos e os encorajam às tomadas de decisões referentes à escolha profissional.

Assim sendo, o presente trabalho de pesquisa e investigação norteou-se a partir dos princípios teóricos de Bohoslavsky (1993), Bock, (1995), Bock (2006), Oliveira (2008), Lucchiari (1993); entre outros; dividiu-se em quatro momentos interrelacionados entre si e não necessariamente obedecendo a seguinte ordem:

\section{1- O SIGNIFICADO DA ESCOLHA PROFISSIONAL \\ 2- O TRABALHO \\ 3- AUTOCONHECIMENTO E INFORMAÇÃO PROFISSIONAL \\ 4- FAMÍLIA}

Os encontros foram baseados em Bock (1995), Bock (2006), Luchiari (1993), Oliveira (2008), Fritzen (2009).

\section{Procedimentos para análise dos dados}

As perguntas abertas dos questionários inicial e final foram analisadas mediante o método de análise de conteúdo (BARDIN, 2010). Adotou-se o critério semântico para 
a identificação de categorias temáticas, baseadas no agrupamento de elementos de significados mais próximos, que compunham as respostas dos participantes. Após esta categorização as respostas foram organizadas em quadros demonstrativos para que se pudesse observar e conhecer os conceitos elaborados pelos sujeitos.

\section{Os encontros}

Durante o desenvolvimento da pesquisa foram realizados 10 , com a duração de aproximadamente uma hora e trinta minutos, na própria Universidade, sendo o horário das $17 \mathrm{~h} 30$ às 19h00. Participaram da pesquisa 13 sujeitos com idades entre 16 e 19 anos, no período de março a junho de 2012, desses três (3) eram do sexo masculino e $\operatorname{dez}(10)$ do sexo feminino.

Durante os encontros os sujeitos da pesquisa realizaram atividades diversificadas, como responder a questionários, dinâmicas de grupos, discussão e desenvolvimento de pesquisas contendo diversas informações profissionais. Assim, a partir do primeiro encontro os sujeitos responderam questões referentes à escolha profissional, trabalho, mercado e campo de trabalho, informações profissionais e temas relativos ao autoconhecimento, família, projetos de vida pessoal e profissional.

\section{Resultados e discussão}

De início, quando questionados sobre a escolha profissional ser a mais importante, os sujeitos, afirmaram que sim, seria uma escolha para a vida toda, posteriormente após refletirem conseguem perceber que é uma das escolhas mais importantes de suas vidas.

Para escolher com segurança os jovens devem pensar, segundo Garbulho (2009), que tipo de profissional pretendem ser e como concebem o compromisso social da categoria escolhida. Uma forma de ajuda para a escolha da profissão é serem estimulados a terem um projeto de vida pessoal e profissional considerando o contexto social em que estão inseridos. Para isso é essencial reflexão, compreender o mundo para além do aparente. Buscar um sentido e um significado no trabalho que ultrapasse a mera obtenção de sucesso, de prestígio e dinheiro. Para realização desses aspectos é fundamental um melhor conhecimento de si mesmo. 
Segundo Garbulho (2009), o autoconhecimento é fundamental, o aluno necessita se conhecer, saber o que lhe desperta interesse e como ele se imagina daqui a 10 ou 15 anos, são pontos importantes para definir o caminho a ser tomado.

No questionário inicial, Quadro 1, a maioria dos sujeitos, S2, S6, S9, S10, S11, S13, responderam que a escolha da profissão era uma das mais importantes de suas vidas, apenas três sujeitos acreditavam que seria uma escolha para a vida toda, S1, S3 e S4. Três sujeitos, o cinco (S5), sete (S7) e oito (S8) afirmavam que a escolha da profissão era a mais importante de suas vidas.

Quadro 1: $1^{\circ}$ Semestre de 2012. A Escolha Profissional é a escolha mais importante de sua vida? $(\mathrm{N}=13)$ Questionário Inicial.

\begin{tabular}{|l|l|l|l|l|l|l|l|l|l|l|l|l|l|}
\hline & S1 & S2 & S3 & S4 & S5 & S6 & S7 & S8 & S9 & S10 & S11 & S12 & S13 \\
\hline Para o resto da vida & X & & X & X & & & & & & & & & \\
\hline $\begin{array}{l}\text { Uma das mais } \\
\text { importantes }\end{array}$ & & X & & & & X & & & X & X & X & & X \\
\hline Sucesso no trabalho & & & & & X & & & & & & & & \\
\hline Sim & & & & & X & & X & X & & & & & \\
\hline
\end{tabular}

Fonte: Autoria própria.

O Quadro 2 trata do questionário final quando os sujeitos foram novamente indagados sobe a escolha profissional e nesse as respostas apareceram de forma mais completa e argumentada. Observa-se que naquele momento oito (8) sujeitos (S1, S2, S3, S4, S6, S11, S12, S13), afirmaram que a escolha da profissão é uma das escolhas mais importantes e argumentaram muito bem. O sujeito dois (2): "Escolher a minha profissão é muito importante, mas na vida também quero um dia escolher uma pessoa, namorar, casar e ter uma família”.

Escolher algo que se goste e acredite ser útil às pessoas também apareceu na fala dos sujeitos S2, S3, S4, S6, S9, S10, S11, S12, S13, como nos exemplos abaixo:

O sujeito dez (10) diz no debate após preencherem o questionário: “Meu pai nunca pode escolher que curso faria, trabalha no banco, mas não gosta” O sujeito dois (2) argumenta: "Quando penso em fazer química penso na possibilidade de ser muito útil na resolução de crimes, hoje em dia existem alguns produtos químicos que desvendam impressões digitais, sangue, acho que serei importante, útil para as pessoas que passam por este tipo de problema" 
Quadro 2: $1^{\circ}$ Semestre de 2012. A Escolha Profissional é a escolha mais importante de sua vida? $(\mathrm{N}=13)$ Questionário Final.

\begin{tabular}{|l|l|l|l|l|l|l|l|l|l|l|l|l|l|}
\hline & S1 & S2 & S3 & S4 & S5 & S6 & S7 & S8 & S9 & S10 & S11 & S12 & S13 \\
\hline $\begin{array}{l}\text { É uma das escolhas mais } \\
\text { importantes }\end{array}$ & $\mathrm{X}$ & $\mathrm{X}$ & $\mathrm{X}$ & $\mathrm{X}$ & & $\mathrm{X}$ & & & & & $\mathrm{X}$ & $\mathrm{X}$ & $\mathrm{X}$ \\
\hline $\begin{array}{l}\text { Escolher algo em que eu } \\
\text { acredite, goste e seja útil }\end{array}$ & & $\mathrm{X}$ & $\mathrm{X}$ & $\mathrm{X}$ & & $\mathrm{X}$ & & & $\mathrm{X}$ & $\mathrm{X}$ & $\mathrm{X}$ & $\mathrm{X}$ & $\mathrm{X}$ \\
\hline $\begin{array}{l}\text { Escolher algo que tenha } \\
\text { um bom campo de } \\
\text { trabalho, ter um bom } \\
\text { futuro financeiro }\end{array}$ & $\mathrm{X}$ & & $\mathrm{X}$ & & & $\mathrm{X}$ & & $\mathrm{X}$ & & & & & \\
\hline
\end{tabular}

Fonte: Autoria própria.

No que se refere à concepção de trabalho, no questionário inicial, pudemos verificar no Quadro 3 que a opção trabalho como sobrevivência foi escolhido por 4 sujeitos, S3, S7, S8 e S11, isto reforça o que Bock (1986, p. 174) afirma: “A maioria da população brasileira não escolhe sua profissão na medida em que a questão fundamental é a busca da sobrevivência física, e a questão de uma possível realização pessoal não se coloca."

Quadro 3:1 $1^{\circ}$ Semestre de 2012 - Concepções do tema trabalho $(\mathrm{N}=13)$ Questionário Inicial

\begin{tabular}{|l|l|l|l|l|l|l|l|l|l|l|l|l|l|}
\hline & S1 & S2 & S3 & S4 & S5 & S6 & S7 & S8 & S9 & S10 & S11 & S12 & S13 \\
\hline $\begin{array}{l}\text { Utilidade desenvolvimento para } \\
\text { a sociedade }\end{array}$ & $\mathrm{X}$ & $\mathrm{X}$ & & $\mathrm{X}$ & & $\mathrm{X}$ & & & & $\mathrm{X}$ & $\mathrm{X}$ & & \\
\hline Ajudar os menos favorecidos & $\mathrm{X}$ & & & & $\mathrm{X}$ & & & & & & & & \\
\hline Trabalho como sobrevivência & & & $\mathrm{X}$ & & & & $\mathrm{X}$ & $\mathrm{X}$ & & & $\mathrm{X}$ & & \\
\hline Amadurecimento Pessoal & & & & & $\mathrm{X}$ & & & & & & & $\mathrm{X}$ & \\
\hline Autonomia Financeira & & & & & & $\mathrm{X}$ & $\mathrm{X}$ & & $\mathrm{X}$ & $\mathrm{X}$ & & $\mathrm{X}$ & $\mathrm{X}$ \\
\hline Gostar do trabalho & & & & & & & & & $\mathrm{X}$ & & & & $\mathrm{X}$ \\
\hline
\end{tabular}

Fonte: Autoria própria.

Quanto à concepção de trabalho como desenvolvimento da sociedade e autonomia financeira, citamos Tittoni (1994, p. 25), que traz como definição de trabalho “[...] uma possibilidade de inscrição nas relações sociais e como meio através do qual o trabalhador sente-se útil produzindo coisas, considerando-se também as limitações e características do processo de trabalho [...]”. Isto ficou evidenciado na fala dos sujeitos ao relatarem o trabalho como Utilidade e desenvolvimento para a sociedade, sujeitos $\mathrm{S} 1$, S2, S4, S6, S10 e S11.

O sujeito dois (S2): "Com meu trabalho posso descobrir novos medicamentos". 
Tittoni (1994) quanto ao emprego cita Singer (1998), que o define como a aplicação da força de trabalho no sentido de ter rendimentos consequentes da produção de bens e serviços, encontramos uma categoria que reafirma o que colocam esses autores, trabalho como Autonomia Financeira.

Quadro 4: $1^{\circ}$ Semestre de 2012 - Concepções do tema trabalho $(\mathrm{N}=13)$ Questionário

\begin{tabular}{|l|l|l|l|l|l|l|l|l|l|l|l|l|l|}
\hline & S1 & S2 & S3 & S4 & S5 & S6 & S7 & S8 & S9 & S110 & S11 & S12 & S13 \\
\hline $\begin{array}{l}\text { O trabalho como progresso } \\
\text { de vida pessoal e profissional }\end{array}$ & $\mathrm{X}$ & $\mathrm{X}$ & $\mathrm{X}$ & $\mathrm{X}$ & & $\mathrm{X}$ & & & & $\mathrm{X}$ & $\mathrm{X}$ & $\mathrm{X}$ & $\mathrm{X}$ \\
\hline $\begin{array}{l}\text { Trabalho e a importância de } \\
\text { realizar algo que goste }\end{array}$ & & $\mathrm{X}$ & & $\mathrm{X}$ & & $\mathrm{X}$ & & & & $\mathrm{X}$ & & & $\mathrm{X}$ \\
\hline $\begin{array}{l}\text { O estudo e a possibilidade de } \\
\text { realizar um trabalho } \\
\text { intelectual }\end{array}$ & & $\mathrm{X}$ & & & & & & & & & & & \\
\hline $\begin{array}{l}\text { A importância da graduação } \\
\text { para aumentar as } \\
\text { possibilidades de atuação }\end{array}$ & $\mathrm{X}$ & $\mathrm{X}$ & & & & & & & & & & & \\
\hline
\end{tabular}

Fonte: Autoria própria.

Os instrumentos utilizados durante a execução do projeto possibilitaram a constatação do processo de conscientização pelos sujeitos dos múltiplos fatores que influenciam na escolha profissional, tais como: família, amigos, mídia, as relações sociais, culturais e econômicas, como afirma Bock (2006). Algumas falas dos sujeitos indicam o dilema que sentem por algumas influências que sofrem:

- "Meus pais prefeririam que eu fizesse medicina, mas eu não tenho jeito, não gosto, prefiro pensar em química, acho muito melhor para mim”, sujeito dois (2).

- Outra fala sobre a influência, vista pelo sujeito como algo positivo:

“Cresci vendo meus primos fisioterapeutas eu acho muito bonita e útil a profissão, quero ser fisioterapeuta também”, sujeito onze (11).

Sobre informação profissional e autoconhecimento, iniciamos o encontro com dinâmica baseado em Oliveira (2008), "Minha Bandeira Pessoal”, onde os adolescentes foram estimulados a falar sobre suas qualidades pessoais positivas, seus 
talentos. É comum na adolescência observarem somente os defeitos, assim reclamam do cabelo ou porque é liso demais ou crespo demais, ou porque é magro demais ou gordo demais, como ressalta Aberestury \& Knobel (1981), os adolescentes estão num processo de construção de identidade e luto pela perda do corpo infantil, avanços e retrocessos contínuos. Com o andamento da dinâmica os sujeitos puderam perceber que todos nós temos qualidades e aí tivemos os seguintes depoimentos:

- "Tenho paciência com crianças e pessoas idosas; gosto de aprender e estudar; gosto do contato humano; sou boa em limpar a casa." Sujeito onze (11).

- "Gosto de cuidar; gosto de crianças; tenho paciência; e gosto de ajudar as pessoas", sujeito seis (6).

- "Sou bom para jogar bola; em matérias exatas; gosto de computador; de sair com os amigos; tenho paciência; gosto de viajar e de futebol." Sujeito três (3).

- "Sou comunicativo, as pessoas dizem, gosto de falar com as pessoas." Sujeito dois (2).

- "Gosto de cozinhar; sou dedicada ao estudo; gosto de fazer trabalhos manuais; tenho paciência e cuidado com os outros." Sujeito quatro (4).

- "Sou comunicativa; gosto de animais; sou prestativa; gosto de conversar, de viajar e de sair com os amigos." Sujeito dez (10).

- "Gosto de jogar futebol; gosta de computador; sou alegre; participativo e gosto de comer." Sujeito doze (12).

Ainda estimulando o autoconhecimento realizamos uma reflexão sobre os hábitos de estudo de cada um visando à preparação para o vestibular, assim, na lousa organizamos um quadro do que seria o horário real de estudos de cada um e como eles entendem que deveria ser o horário ideal. Ao final concluímos juntamente com o grupo que é necessário muito estudo, dedicação, mas um tempo para o descanso, onde foi ressaltada a necessidade de se ter uma organização do tempo diário para o estudo, bem como para o descanso e integração com família. Por meio dessa organização os sujeitos puderam refletir que muitos fatores influenciam na organização do cronograma de estudo diário, portanto é necessário ter disciplina, planejamento para alcançar os objetivos, pois como aponta Oliveira (2008), existe um tripé a respeito do que é “desejável, possível e realizável naquele momento", para conseguirmos a realização de nossos projetos de vida pessoal e profissional.

Desenvolvemos o tema família e a integração do grupo com os pais, visto que é de fundamental importância no que tange ao apoio a seus filhos nesse momento tão angustiante e decisivo de transição da adolescência para a vida adulta. 
Com a participação dos pais pudemos registrar alguns depoimentos em relação ao projeto, como podemos exemplificar abaixo:

- $\quad$ Pai do sujeito dez (10) verbalizou que é bancário há muitos anos, mas que não teve a opção de escolha, não gosta do que fez, mas fica feliz em saber que sua filha teve a oportunidade com o curso, de escolher uma profissão que goste. Ele cita que a filha foi entrevistar alguns profissionais da área de seu interesse.

- $\quad$ Mãe do sujeito um (1) diz: "Ele escolheu química, vamos ver, se fizer bem feito tenho a certeza que dará certo.".

- $\quad$ Mãe do sujeito treze (13) verbaliza "o aproveitamento que minha filha teve no curso foi muito grande, desmistificando alguns medos que tinha sobre medicina, como desmaiar quando visse sangue e ao mesmo tempo ela se interessou em visitar com sua escola uma faculdade de medicina, foi ao laboratório de anatomia e gosta de ver a realidade de todas as séries médicas da TV".

- $\quad$ Mãe do sujeito doze (12) conta que seu filho desde pequeno fala de fisioterapia, mas ainda fica um pouco surpresa com a escolha dizendo: “os primos contam também das dificuldades que passam lá, e mesmo assim ele quer então tudo bem.".

- $\quad$ Pai do sujeito oito (8) afirmou ser o curso de moda a opção da filha e que temia pelo campo de trabalho, mas que respeitaria a opção.

- $\quad$ As mães dos sujeitos doze (12) e seis (6) demonstraram certa satisfação não só com as escolhas que as filhas fizeram, mas também pela certeza de que elas vão fazer um curso superior e ter uma profissão.

- $\quad$ Mãe do sujeito quatro (4) que não havia feito uma escolha profissional, coloca que mesmo assim acredita que os encontros foram válidos e quanto às dúvidas restantes ela auxiliaria a filha no sentido de levá-la a uma Universidade que tem o curso de ecologia.

\section{Conclusão}

Os resultados deste estudo mostram que a disciplina de Orientação Profissional na formação de professores é muito importante, visto que enfatiza mais uma função que o pedagogo pode desempenhar e sua possibilidade de atuação na escola e no mercado de trabalho. 
Verificamos que pensar a escolha profissional e o tema trabalho é para o aluno que irá prestar o vestibular fundamental para que possa pensar a escolha de forma mais consciente, refletindo que ela é multideterminada.

Observou-se que participar de atividades que estimulam autoconhecimento e a informação profissional é muito motivador para um aluno que precisa se conhecer melhor, obter informações sobre as diversas profissões e sobre a construção de uma carreira no século XXI.

Com o referencial utilizado, os 13 (100\% dos alunos) conseguiram elaborar um projeto de vida pessoal e profissional, fato esse que inclusive os impulsionou a estudarem mais.

Esperamos que a presente pesquisa possa ser útil na reflexão sobre o currículo dos cursos de formação dos futuros professores, onde os mesmos tenham oportunidade de estudar, pesquisar e observar a contextualização da teoria na prática, deste modo auxiliando também a população tão carente de serviços como este.

\section{REFERÊNCIAS}

ABERASTURY, A.; KNOBEL, M. Adolescência normal: um enfoque psicanalítico. Porto Alegre: Artmed, 1981.

BARDIN, L. Análise de conteúdo. 4. ed. Lisboa: Edições 70, 2010.

BOCK, A. M. B. et al. A escolha profissional em questão. São Paulo: Casa do Psicólogo, 1995.

BOCK, S. D. “Trabalho e profissão". In: CONSELHO REGIONAL DE PSICOLOGIA; SINDICATO DOS PSICÓLOGOS NO ESTADO DE SÃO PAULO. Psicologia no ensino de $\mathbf{2}^{\circ}$ grau: uma proposta emancipadora. São Paulo: Edicon, 1986.

BOCK, S. Orientação profissional: abordagem sócio-histórica. 3. ed. São Paulo: Cortez, 2006.

BOHOSLAVSKY, R. Orientação vocacional: a estratégia clínica. São Paulo: Martins Fontes, 1993.

FERRETI, C. J. Formação profissional e reforma do ensino técnico: anos 90. Caderno Cedes, Campinas, ano 17, n. 59, 1997. 
FRISCHENBRUDER, S. L. Sobre o final da adolescência: o lugar da profissão na passagem á vida adulta. In: LASSANCE, M. C. P. et al. Intervenção e compromisso social. São Paulo: Vetor, 2005. (Orientação profissional: teoria e técnica, v. 2).

FRITZEN, S. J. Exercícios práticos de dinâmica de grupo. 38. ed. Petrópolis: Vozes, 2009. v. 1.

GARBULHO, N. F. Auxílio na hora de escolher a carreira. In: UNIVERSIDADE ESTADUAL PAULISTA. Guia de Profissões 2009. São Paulo: Assessoria de Comunicação e Imprensa da UNESP: Fundação Vunesp, 2009.

LUCCHIARI, D. H. P. S. Técnicas de orientação profissional. In: LUCCHIARI, D. H. S. (Org.) Pensando e vivendo a orientação profissional. São Paulo: Summus, 1993. p. 35-68.

OLIVEIRA, O. B. A orientação vocacional e profissional no ensino médio: a possibilidade de um planejamento global. In: LISBOA, M. D.; SOARES, D. H. P. (Org.) Orientação profissional em ação: formação e prática de orientadores. 2. ed. São Paulo: Summus, 2000. p. 98-110.

OLIVEIRA, M. B. L. Orientação vocacional: relato de intervenção. 2008. Trabalho apresentado ao CNPq pela Coordenadora de Orientação Profissional da UNESP Campus de Araraquara.

TITTONI, J. Subjetividade e trabalho. Porto Alegre: Ortiz, 1994.

THIOLLENT, M. Metodologia da pesquisa-ação. 16. ed. São Paulo: Cortez, 2008. (Coleção temas básicos de pesquisa-ação).

VIGOTSKY, L. S. A formação social da mente. 4. ed. São Paulo: Martins Fontes, 1991.

\section{Como referenciar este artigo}

DÁTILO, Gilsenir Maria Prevelato de Almeida. A necessária disciplina de orientação profissional na formação de professores para o século XXI. Revista Ibero-Americana de Estudos em Educação, Araraquara, v. 11, n. 4, p. 1835-1848, 2016. Disponível em: <http://dx.doi.org/10.21723/riaee.v11.n4.6306>. E-ISSN: 1982-5587.

Submissão em: setembro/2013

Aprovação final em: julho/2016 